\begin{tabular}{lll}
\hline MEKIF ÜNIVERSITESI & Insan ve Toplum Bilimleri Dergisi \\
2010 & FSM Scholarly Studies
\end{tabular}

\title{
Giovanni Molino'nun 1641 Yılında Yayımlanan Dittionario Della Lin- gua Italiana-Turchesca İsimli Eserinde Bazı Türkçe Yardımcı Fiiller Üzerine
}

Ewa Siemieniec-Gołaś *

Özet

Çev. Gülderen Tokmak **

Türkçe bazı fiillerin temel fonksiyonlarının yanı sıra isim kalıplarıyla birleşik fiiller oluşturan yardımcı bir görevi de vardır. Bu görev sadece modern Türkçede değil aynı zamanda Osmanlı Türkçesinde de bilinmektedir. Bu makalenin amacı etmek, olmak, eylemek, kılmak fiillerinin bu görevdeki kullanımlarına örnek göstermektir.

Giovanni Molino’nun 17. yy İtalyanca-Türkçe Sözlük'ünden alınan sözcük örnekleri incelemenin temelini oluşturmaktadır. Örnekleri incelediğimizde, Osmanlı Türkçesinde bilhassa etmek fiilinin, nispeten daha az da olmak fiilinin birleşik fiillerin oluşumu sürecinde sıklıkla yer aldığını, bununla birlikte eylemek ve kılmak fiillerinin nadiren bu fonksiyonu yerine getirdiğini belirtebiliriz. Aslında, etmek ve olmak fiillerinin modern Türkçede hâlâ bu fonksiyonu yerine getirdiği; ancak bunun Osmanlı Türkçesinde aynı ölçüde olmadığı gözlemlenebilir.

Anahtar Kelimeler: Osmanlı Türkçesi, Türkçede yardımcı fiiller.

\section{On Some Turkish Auxiliary Verbs In Giovanni Molino's Dittionario Della Lingua Italiana, Turchesca (1641)}

\section{Abstract}

Some Turkish verbs, besides their basic function, have an auxiliary function, forming compound verbs with nominal forms. This function is known not only in modern Turkish but also in Ottoman-Turkish. The purpose of this paper is to present the verbs etmek, olmak, eylemek, kllmak as examples of this function.

The lexical material excerpted from Giovanni Molino's seventeenth-century Italian-Turkish Dictionary constitutes the basis for the analysis. When analysing the material we can ascertain that in Ottoman-Turkish the verb etmek especially was frequently involved in the process of forming compound verbs, olmak rather less so, with eylemek and k1lmak rarely performing this function. Indeed, the verbs etmek and olmak can still be observed to perform this function in modern Turkish, however, not on the same scale as in Ottoman-Turkish.

Keywords: Ottoman Turkish, Auxiliary verbs in Turkish.

* Prof. Dr. Ewa Siemieniec-Gołaś “On Some Turkish Auxiliary Verbs In Giovanni Molino’s Dittionarı Della Lingua Italiana, Turchesca (1641)" Studia Linguistica, cilt 127, 2010. Jagellon Üniversitesi, Kraków/Polonya, e-posta: udsiemie@cyf-kr.edu.pl

** Arş. Gör. Abant-İzzet Baysal Üniversitesi, Fen-Edebiyat Fakültesi, Türk Dili ve Edebiyatı Bölümü, Bolu/Türkiye, gulderentokmak@ibu.edu.tr 
Diğer diller gibi Türkçenin de yardımcı filleri vardır. Ancak, araştırmacılar arasında tutarlı bir görüş olmadığından Türkçe yardımcı fiillerin tam bir listesini vermek zordur. Gencan'a göre ${ }^{1}$ Türkçede yardımcı fiil fonksiyonunu gören sadece dört fiil vardır:

Ad soylu sözcüklere iş, devim, kılış ve yargı anlamı katan ve asıl görevi bu olan sözcüklere yardımcı eylem denir. Yardımcı eylemlerin başlıcaları şunlardır: etmek, eylemek, olmak, kllmak...

Lewis ${ }^{2}$ yapmak ve buyurmak fillerinin de ayrıca bu yardımcı fiil fonksiyonunda olduğunu belirtir. Buyurmak fiili için şu açıklamayı yapar: buyurmak tam olarak emretmek anlamına gelir ve zarif bir konuşmada etmek ve eylemek'i de içine alan diğer fiillerin yerine kullanılmıştır.

Son zamanlarda yayımlanan Türkçe gramer kitabının yazarları biraz daha farklı bir bakış açısıyla şöyle yazmıştır:

Bir yardımcı fiil tek başına kullanılamaz, başka bir fiil ya da isimle birlikte kullanılır. Türkçede yardımcı fiilin üç türü vardır:

i. Bağlı yardımcı fiiller: Ekler bunlardır: -(y)Abil-, -(y)Iver-, -(y)Ayaz, -(y) Adur, -(y)Akal.

ii. Bağımsız yardımc filler: Bunlar ol- (aynı zamanda bu fiil cevheri filin şekillerinden biridir), et-, gel-, dur-, kal-, düş-, bulun-, eyle-ve buyur- gibi fiillerdir.

iii. $i-/-y$ - Bunlar da cevheri filin şekilleriden biridir... ${ }^{3}$

Yazarların, ilk cümlede açık bir şekilde belirttikleri alıntılanan hatalı görüşe rağmen bu bölüme katılmamak zordur. Aslında bu açıklama daha çok i. maddesi ve iii. maddesine gönderimde bulunmuş gibi görünebilir; ancak yazar tarafından "bağımsız yardımcı filler" olarak adlandırılan bu fiiller yardımcı fiil değildir; çünkü ii. maddedeki bu fiiller fonksiyon olarak münferit fiillerdir ve bu fiillerin kendi anlamları vardır. Örneğin; et- , gel- , dur- vb. Fakat, aynı zamanda bu fiiller yardımcı filller gibi görev yaparlar.

Majda $^{4}$ Türk dilini içeren kitabında birleşik filler meselesini analitik ve sözdizimsel olarak iki guruba ayırmak suretiyle kısaca değerlendirir. Türkçe yardımc1 fiillerin örneği olarak şunları sıralar: olmak, etmek, bulunmak, kllmak. Türkçede bu fonksiyonda çok sayıda anlamca kaynaşmış ve deyimleşmiş yardımcı fiil olarak kullanılan daha başka birçok fiilin varlığından bahseder. Örneğin; almak,

1 Tahir Nejat Gencan, Dilbilgisi, İstanbul, 1971, s. 268.

2 Geoffrey Lewis, Turkish Grammar, Oxford, 1975, s. 154- 156.

3 Aslı Göksel - Celia Kerslake, Turkish: A Comprehensive Grammar, London, New York, 2005, s. 156.

4 Tadeusz Majda, Rozwój Jezyka Tureckiego w XVII wieku, Warszawa, 1985, s. 85. 
açmak, bulmak, çekmek, durmak, gelmek, kalmak, vermek vb.

Stachowski, son yayımlanan gramer kitabında ${ }^{5}$ durmak, gelmek, gitmek, görmek, kalmak, vermek, yazmak gibi seçilmiş olan yardımcı fillleri pek çok kullanımıyla listeler. olmak ve etmek fiillerine fiillerin yapılarını ve çatılarını tanımlarken değinir ${ }^{6}$.

Yardımcı fiiller Osmanlı Türkçesinde de kullanılmıştır. 17. yy'da Giovanni Molino tarafindan yazılan İtalyanca-Türkçe Sözlük'te Türkçenin konuşma dili örneğinin zenginliğine ulaşılabilir. ${ }^{7}$ Molino'nun eseri sadece temel anlamlı filleri içermez, aynı zamanda yardımcı fiil fonksiyonunu yerine getiren bazı fiilleri de içerir.

Molino'nun eserinin sözcük örnekleri incelendiğinde yardımc1 görevde en s1k kullanılan fiillerin etmek ve olmak filleri olduğu belirtilebilir. Bu filler pek çok söz öbeği ve deyimde mevcuttur. Eylemek ve kllmak fiilleri Osmanlı Türkçesinde çok sık kullanılan fiiller olmasına rağmen Molino'nun sözlüğünde çok nadiren görülmüştür. buyurmak fiili de incelenmiş olan örneklerde sadece bir kere geçmiştir. Ancak, bu incelemede bu fiili göz önünde bulundurmadık, çünkü Molino'nun sözlügünde sadece fiilin temel konuşma dilindeki anlamı yer almaz aynı zamanda isimleşmiş anlamı da yer alır. mş: buyurmak (buiurmak) 'statuto, ordinatione'(430).

Bu sebepten, mevcut inceleme birleşik fiillerde etmek ve olmak fiillerinin yardımcı görevleri ve bazı durumlardaki anlamca kaynaşmış ve deyimleşmiş fiiller üzerine yoğunlaşmıştır. Bazı anlamca kaynaşmış birleşik filleri kılmak ve eylemek fillleriyle kullanırız; ancak Molino'nun sözlüğünde eylemek fiili sadece bir kez, kılmak fiili ise iki kez görülür.

etmek (etmek) (142);

adavet etmek (adauet etmek) "abominare" (5); adavet etmek (adauet etmek) 'odiare, portar' odio' (278) - mş.: adavet "Düşmanlık, nefret."

adet etmek (adet etmek) "vsare" (488) - mş.: adet "Âdet, alışkanlık, örf."

af etmek (af etmek) "perdonare" (299) - mş.: affetmek "1.Bağışlamak. 2. Ku-

5 Marek Stachowski, Gramatyka Jezyka Tureckiego w Zarysie, Kraków, 2007, s. 377-381.

6 Stachowski, a.g.e., s. 246.

7 Giovanni Molino bir 17. yy Türk dili tercümanı ve 1641 yılında Roma'da yayımlanmış olan Dittionario della lingua Italiana, Turchesca'nın yazarıdır. Yazar ve çalışmaları hakkında daha fazla bilgi için bakınız: Milan Adamović, "Giovanni Molino und seine türkische Grammatik" Acta Linguistica Academiae Scientiarum, cilt 24, 1974, s. 37- 67. Elżbieta Święcicka, "Interpreter Yovhannes Ankiwrac'i also called Giovanni Molino" , Folia Orientalia, cilt 36, 2000, s. 329-342. Asım Tanış, Giovanni Molino'nun Italyanca-Türkçe Sözlügü ve Halk Türkçesi, Ankara, 1989. Ewa Siemieniec- Gołaś Turkish lexical content in Dittionario della Lingua Italiana, Turchesca by Giovanni Molino (1641), Kraków, 2005. 
suruna bakmamak. 3.Hoşgörü ile karşılamak, mazur görmek."

aforoz etmek (afforos etmek) "scommunicare" (386) - mş.: afaros, aforoz etmek "Hristiyanlıkta kilise tarafından cemaatten kovmak, darılıp biriyle konuşmamak, ilgiyi kesip kendinden uzaklaştırmak, toplum diş1lamak."

ag̀ır gün etmek (aghir ghiun etmek) "solẽnizzare" (409) - mş.: kutlamak, bayram yapmak "Önemli bir olayın gerçekleşmesinin yıl dönümü dolayısıyla tören yapmak."

ah etmek (ah etmek) "sospirare" (414) - mş.: ah etmek "Ac1 ile içini çekmek, ilenmek."

ahri etmek (achri etmek) "cessare, finire" (87); ahir etmek (achr, etmek) "compire, finire" (99); ahrin etmek (achrin etmek) "finire" (148); ahrin eda etmek (achrin eda etmek) "terminare, finire" (453) - mş.: ahir olmak "Sona ermek, bitmek."

alay etmek (alai etmek) "resegnare" (342) - mş.: alay etmek "Bir kimsenin, bir şeyin, bir durumun, gülünç, kusurlu, eksik vb. yönlerini küçümseyerek eğlence konusu yapmak, dalga geçmek."

alış veriş etmek (alisc verisc etmek) "traficare, mercantare" (462); alıs veriş etmek (alisc verisc etmek) "trattare, negotiare, maneggiare" (465) - mş.: alı̧̧veriş etmek "Ticaret yapmak, mal alıp vermek."

amma etmek (amma etmek) "acciecare" (7) - Modern kaynaklarda böyle bir birleşik fiil kaydedilmemiştir.

arz etmek (arsz etmek) "anuisare" (64); arz etmek (arsz etmek) "significare" (404) - mş.: arz "Sunma, yüksek bir makama anlatma, bildirme, belirtme."

arzu etmek (arsu etmek) "bramare, desiderare" (73); arz [u] etmek (arsz etmek) "supplicare, dimandar in gratia" (443) - mş.: arzu etmek "Dilemek, yürekten istemek, arzulamak."

ayan etmek (aian etmek) "illustrare" (190); ayan etmek (aian etmek) "manifestare" (243); ayan etmek (aian etmek) "palesare" (289); ayan etmek (aian etmek) "reuelare" (343); ayan etmek (aian etmek) "suelare, scoprire" (440); ayan eşkere etmek (aian esc-kiere etmek) "publicare, palesare" (327); sözini ayan etmek (sosini aian etmek) "spremere" (425) - mş.: ayan "Açık, net, âşikâr, belli."

aydınluk etmek (aidinluk etmek) "schiarire, far chiaro" (382) - mş.: aydınlık "1.Bir yeri aydınlatan güç, 1şık. 2.Berrak, parlak."

ayıb etmek (aib etmek) "disonestare" (123) - mş.: ayıp "Toplumun ahlak kurallarına aykırı olan, utanılacak durum veya davranış; utanç veren, yüz kızartan."

azad etmek (aszad etmek) "assoluere, liberare” (62); azad etmek (aszad et- 
mek) "liberare, mettere in liberta" (233); azad etmek (aszad etmek) "soluere, liberare" (410) - mş.: azad etmek "Serbest birakmak, salıvermek."

batal etmek (batal etmek) "suspendere" (443) - mş.: battal etmek "Bir belgeyi resmi olarak iptal etmek."

bazırganlık etmek (basirghianlik etmek) "trafficare, mercantare" (462) - mş.: sadece: bazargan "Tüccar."

bend etmek (bend etmek) "legare" (230) - mş.:bend etmek "Bağlamak, kilitlemek, kendine bağlamak."

berbad etmek (berbad etmek) "annullare" (52) - mş.: berbad etmek "Mahvetmek, bozmak."

betdua etmek (betduua etmek) "maledire" (241) - mş.: beddua etmek "Illenmek, intizar etmek."

beyan etmek (beian etmek) "dechiare" (114); beyan etmek (beian etmek) "esplicare" (136); beyan etmek (beian etmek) "illustrare" (190) - mş.: beyan etmek "Anlatmak, açıklamak, bildirmek."

beylik etmek: zulüm ile beylik etmek (szulumilhe beiligh etmek)" tiranniggiare, dominare per forza" (456) - mş.: beylik "Beylik; eyalet; bir beyin yönetimi altındaki bölge."

böhden etmek (bohden etmek) "calumniare, ò vero incolcolpare" (77) - mş.: bühtan etmek "Haksız yere suçlamak, iftira etmek."

biretmek (biretmek) "vnire" (485) - mş.: bir "Sayıların ilki; benzer; bir kez; sadece."

birlik etmek (birlik etmek) "concardare" (100) - mş.: birlik "Bütünlük, bir olma durumu, uyum."

cafa etmek (giafa etmek) "affligere" (24); cafe etmek (giafe etmek) "molestare" (259); cafa etmek (giafa etmek) "persecutione" (301); gendisine cafa etmek (ghiendisine giafa etmek) "struggersi" (438) - mş.: cefa etmek "Acı çektirmek, azap çektirmek."

cazılık etmek (giasilik etmek) "fatturare" (143); cazlluk etmek (giasiluk etmek) "stregare" (435) - mş.: cadl/ cadu "Cad1, büyücü."

cem etmek (gem etmek) "accumulare, amassare" (13); cem etmek (giem etmek) "sommare" (411); nokrayl cem etmek (nokrai gem etmek) "radunar dinari" (335) - mş.: sadece: cem "Toplama, yığın, grup."

cemiyet etmek: halkı cemiyet etmek (halki gemijet etmek) "radunare il populo" (335) - mş.: cemiyet "1.Toplum, birlik. 2.Toplantı."

cevr etmek (gieur etmek) "accorare dare affanno" (10) - mş.: cevr etmek 
"Eziyet etmek, işkence etmek."

çag etmek (ciagh etmek) "diuolgare" (126) - çav etmek ${ }^{8}$ fiiline bak1labilir.

çav etmek (ciau etmek) "promulgare" (322); çav etmek (ciau etmek) "publicare, diuolgare" (327) - mş.: çav "1.Taşraya ait: Ün. 2.Arkaik şekli: "Haber."

datlı etmek (datli etmek) "addolcirsi” (171); datl etmek (datli, etmek) "adolcire" (19); datll etmek (datli etmek) "indolcire" (206); çok datlı etmek (ciokdatli etmek) "adolcire molto" (19) - mş.: tatlı "Şeker tadında olan."

dava etmek (daua etmek) "litigare" (235) - mş.: dava etmek arkaik şekli. "Dava açmak, hak iddia etmek."

davet etmek (dauet etmek) "inuitare" (221); cinleri davet etmek (ginleri dauet etmek) "sconguirare" (386); eşke [?=içki] davet etmek, eşkine [? = içkine ] davet etmek (esc-kine dauet etmek) "inuitare, far brindisi" (221); şerayete davet etmek (sc-eraiete dauet etmek) "citare, chiamare à ragione" (93) - mş.: davet etmek "Çağırmak."

degirmi etmek (deghirmi etmek) "ritondare" (358); degirmi etmek (deghirmi etmek) "rotondare" (364) - mş.: değirmilemek "1.Yuvarlak biçime sokmak 2.Kare biçimine sokmak."

derine etmek (derineg etmek) "congregare, fare adunãza" (22) - dergemek fiili ile karşılaştırılabilir. "Toplamak"

devr etmek (deur etmek) "mouimento, circolare" (264), devretmek (deuretmek) "moto" (264) - mş.: devretmek "1.Bir malın mülkiyetini, bir mal üzerindeki hakkı başkasına geçirmek, aktarmak. 2.Dönmek, dolaşmak."

dilek etmek (dilegh etmek) "intercedere" (218) - mş.: dilek etmek " arkaik şekli "Arzulamak, dilemek."

dua etmek (doua etmek) "benedire" (70) - mş.: dua etmek "Tanr1'ya yalvarmak."

duhul etmek (duhul etmek) "intrare" (219) - mş.: duhul "Giriş, girme."

dügün etmek (dughiun etmek) "far nozze" (274) - mş.: dügüun "Evlenme dolayısıyla yapılan tören."

dümdüz etmek (dumdus etmek) "spianare, appianare" (421) - mş.: dümdüz "Çok düz, tamamen düz."

düz etmek (dus etmek) "spianare" (421) - mş.: düz "Kıvrımlı olmayan, doğru; yüzeyinde girinti çıkıntı olmayan."

eda etmek (eda etmek) "adempire" (18); eda etmek (eda, etmek) "compire,

8 döğ- = döv- örneğindeki gibi fonetik değişikliğin olması mümkündür. 
finire" (99); eda etmek (eda etmek) "sodisfare, contentare" (408); eda etmek: hizmeti eda etmek (hismeti eda etmek) "adẽpire l'offtio" (18) - mş.: eda etmek "Borcunu ödemek; dinî buyrukları yerine getirmek."

ehliberat etmek (ehliberat etmek) "priuilegiare" (319) - mş.: ehil "Bir işte yetkili olan, erbap" + berat "Bir buluştan, bir haktan yararlanmak için devletçe verilen belge, patent; ayrıcalık, imtiyaz."

eksiklik etmek (eghsiklik etmek) "comettere un fallo" (98) - mş.: eksiklik "Eksik olma durumu, noksan; yokluk."

eset etmek (eset etmek) "riuerire" $(359,360)$ - Günümüz kaynakları böyle bir birleşik fiili ya da isim kısmını doğrulamaz.

eşkara etmek (esc-kiaraetmek) "vulgare, palesare" (490) - mş.: eşkere aşikar'ın farklı bir şekli "Açık, belli, meydanda."

evelki kibi etmek (euelki kibi etmek) "tornare à fare come prima" (460) - mş.: etmek "Yapmak"

evlad etmek (eulad etmek) "rifigliare, far figlioli di mono" (347) - mş.: evlad/ evlat "Bir kimsenin oğlu veya kızı, çocuk; ayrıca evlad edinmek "Yasayla belirtilmişs şartlar içinde bir kimseyi evlat olarak nüfusuna geçirmek."

eylik etmek (eylik etmek) "benfare" (71); eylik etmek (eilik etmek) (164) mş.: iyilik etmek "Yararlı işler yapmak, yardımcı olmak."

eyvazın etmek (eiuasin etmek) "render la pariglia" (292); eyvazın etmek (eiuasin etmek) "remunerare" (341); eyvazın etmek (eiuasin etmek) "ricompensare" (346); eyvazın etmek (eiuasin etmek) "rimunerare" (350) - Güncel kaynaklar böyle bir birleşik fiili doğrulamaz.

farakat etmek: işten farakat etmek (isc-den farakatetmek) "abbandonare l'impresa" (3); gendi vicüdinden farakat etmek (ghendi vgiudinden farakat etmek) "abbandonare la vita" (3); günahden farakat etmek (ghiunehden farakat etmek) "ritirarsi da peccati" (358); zamparallkden farakat etmek (szamparalikden farakat etmek) "ritirarsi dal putanesimo" (358) - mş.: ferağ etmek "Hukuki olarak devretmek; çekilmek."

fark etmek (fark etmek) "scernere, discernere" (380) - mş.: fark etmek "1.Ayırt etmek. 2.Değişmek, başkalaşmak."

fayda etmek (faida etmek) "acquistare, guadagnare" (16); fayda etmek (faida etmek) "guadagnare" (172); fayda etmek (faida etmek) "riportare vtile" (353) mş.: fayda "Kâr, yarar, avantaj."

fesad etmek (fesad etmek) "corrompere, guastare" (108) - mş.: fesat etmek "Fesat çıkarmak." 
feth etmek (fet etmek) "domare" (127); feth etmek (fet etmek) "espugnare" (136); feth etmek (fet etmek) "soggiogare" (409) - mş.: fethetmek "Bir yeri veya ülkeyi savaşarak almak."

firar etmek (frar etmek) "fuga, fuggire" (151); firar etmek (frar etmek) scampare, fuggire (378); firar etmek (frar etmek) "scappare, fuggire" (379); tekrardan firar etmek (tekrarden frar etmek) "refugire" (348) - mş. : firar etmek "Kaçmak."

firgaz etmek (firgas etmek) "proclamare" (320); firgaz etmek (firghas etmek) "strillare" (437) - Güncel kaynaklar böyle bir fiili doğrulamaz.

fikir etmek (fikir etmek) "imaginarsi" (191); fikr etmek (fikr etmek) "pensare" (298); fikr etmek (fikr etmek) "speculare, contemplare" (418) - mş.: fikretmek "Enine boyuna düşünmek."

fitnelik etmek (fitnelik etmek) "machinare qualche ingãno" (239) - mş.: fitnelik "Desise, fenalık."

gebe etmek (ghiebe etmek) "ingrauidare" (213) - mş.: gebe etmek "Gebe b1rakmak."

gemicilik etmek (ghiemigiligh etmek) "nauigare" (268); yine gemicilük etmek (iene ghiemigiluk etmek) "rinauigare" (350) - mş.: gemicilik "1.Denizcilik. 2.Deniz yolculuğu, gemi yolculuğu."

ġlaġuzluk [= kılavuzluk] etmek (ghlaghus luk etmek) "guidare" (173) - mş.: kılavuzluk etmek "Yol göstermek, rehberlik etmek."

girift etmek (ghirift etmek) "confiscare" (101) - mş.: girift "Birbirinin içine girip karışmış, girişik, çapraşık."

gölge etmek (ghiolge etmak) "adumbrare" (22) - mş.: gölge etmek "Işı̆̆a engel olmak, gölge yapmak."

gulgule etmek (gulgule etmek) "mormorare" (262) - mş.: gulgule = gulgul "Yaygara, feryat; kuş cıvıltısı, içecekle dolu şişeden çıkan ses."

günah etmek (ghiunah etmek) "peccare, fallire" (296) - mş.: günah etmek = günah işlemek "Günah sayılan davranışta bulunmak."

hadım etmek (chadim etmek) "castrare, tagliare i testicoli” (83) - mş.: hadım etmek "Kısırlaştırmak."

halis etmek (chalis etmek) "refinare" (340) - mş.: halis "Saf, katışıksız; hakiki."

hapis etmek (haps etmek) "imprigionare" (197) - mş.: hapsetmek "Hapse koymak, kapatmak, hapse atmak."

harç etmek (charg'z etmek) "spendere" (419), ziyade harç etmek (sziiadhe chargz etmek) "spendere smisuramente" (420) - mş.: harç "Harcama, gider, 
masraf, borç."

hasıl etmek (hasil etmek) "generare" (160) - mş.: hasıl etmek "1.Ortaya ç1karmak. 2.Elde etmek, ele geçirmek."

hazır etmek (haszir etmek) "apparecchiare” (53); konuklugi hazır etmek (konuklughi haszir etmek) "apparecchiare il conuito" (54); donanmayı hazır etmek (donanmai haszir etmek) "apparecchiare larmata” (53); ziyafeti hazır etmek (szyafeti haszir etmek) "apparecchiare il conuito" (54) - mş.: hazır etmek "Kullanılabilecek duruma getirmek, hazır hâle getirmek."

hazm etmek (hasm etmek) "maltire, digerire" (242); hazm etmek (hasm etmek) "padire, digerire" (288); hazm etmek (hasm etmek) "smaltire, padire" (406) - mş.: hazmetmek" Sindirmek."

hekeyat etmek (hekeiat etmek) "narrare" (267); hekayat etmek (hekiaiat etmek) "raccontare" (335) - mş.: hikaye etmek "Söylemek, ayrıntılarıyla anlatmak."

hekimlik etmek (hekimligh etmek) "medicare" (250) - mş.: hekimlik "1.Hekim olma durumu. 2.Tıbbî bilim, tıp.”

heleşe etmek (helesc-e etmek) "ruzzare, scherzare” (366) - Güncel kaynaklar ne bu fiili ne de bu fiilin isim kısmını doğrular.

hereket etmek (herekiet etmek) "mouere" (264); hereket etmek (herekiet etmek) "mouere" (265); ileri hereket etmek (ileri hereket etmek) "precedere, andar iuanti" (314) - mş.: hareket etmek"1.Devinmek, kımıldamak. 2.Davranmak. 3. Yola çıkmak."

hıyanet etmek (chijanet etmek) "insidiare" (216) - mş.: hıyanet "İhanet, nankörlük, hainlik, vatan hainliği."

hicab etmek (hegiabetmek) "rispettare" (356) - mş.: hicap "1.Utanma, s1k1lma, utanç. 2.Örtü, perde."

hiç etmek (hecz etmek) "annulare" (52), hiç etmek (hecz etmek) "soluere, disfare" (410) - mş.: hiç "Yok."

hise etmek (hese etmek) "diuidere, spartire" (126); hise etmek (hese etmek) "partire, diuidere" (293); hise etmek (hese etmek) "spartire, diuidere" (417) mş.: hisse "Pay."

hizmet etmek (hismet etmek) "seruire” (399) - mş.: hizmet etmek "Görev yapmak, hizmette bulunmak."

hoş etmek: hatırı hoş etmek (chatri hosc etmek) "contẽtare, piacere" (105); hatırını hoş etmek (chatrini chosc-etmek) "sodisfare, contentare" (408) - mş.: hoş "Beğenilen, memnun eden, iyi." 
hoşamet etmek (chosc-amed, etmek) "adulare" (21); hoşamet etmek (chosc-amed etmek) "losingare" (236) - mş.: hoşamed "Hoş karşılama."

höküm etmek (hokum etmek) "comandare" (98); höküm etmek (hokium etmek) "deliberare" (114); hökm etmek (hochm etmek) "reggere, gouernare" (340); höküm etmek (hokum etmek) "sententiare, determinare" (396); höküm etmek (hokum etmek) "statuire, deliberare" (430); ölmege höküm etmek (olmeghe hokum etmek) "sententiato à morte" (396) - mş.: hükmetmek "Yönetmek, egemenliği altında bulundurmak."

hurdahaş etmek (chur da chasc etmek) "frãgere, rõpere" (154) - mş.: hurdu haş "Paramparça, parçalanmış."

1slah etmek (islah etmek) "emendare, correggere" (133) - mş.: 1slah etmek "İyi bir duruma getirmek, iyileştirmek, düzeltmek."

ibadet etmek (ibadet etmek) "orare, pregare" (283) - mş.: ibadet "Bir dinin buyruklarını yerine getirme, tapınma, dini tören."

iftira etmek (iftra etmek) "calumniare, ò vero incolcolpare" (77) - mş.: iftira etmek "Bir suçu birinin üzerine atmak, kara çalmak."

ihmal etmek (ehmal etmek) "scordarsi" (387); ihmal etmek (ehmal etmek) "trascorrere" (464) - mş.: ihmal etmek "Savsaklamak, boşlamak, ilgi göstermemek."

ihtar etmek (iktiar etmek) "credere" (110) - mş.: ihtar etmek "Uyarmak, hatırlatmak, dikkatini çekmek."

ikrar etmek (ikrar etmek) "confessare" (101); ikrar etmek (ikrar etmek) "promettere" (322) - mş.: ikrar etmek "İtiraf etmek, açıkça söylemek."

iktikat etmek (iktikat etmek) "credere" (110) - mş.: itikade etmek "İnanmak."

inkar etmek (inkiar etmek) "negare" (268) - mş.: inkar etmek "Yaptığını, söylediğini, tanık olduğunu saklamak, kabul etmemek."

ilacın etmek (ilagin etmek) "rimediare, prouedere" (349); ilacın etmek (ilagin etmek) "riparare, cioè rimediare" (352) - mş.: ilaç etmek arkaik şekli "Tedavi etmek, çare bulmak."

ilaka etmek (illaka etmek) "hauer da fare con alcuno" (174); ilaka etmek (ilaka etmek) "ingerire" (211) - Modern kaynaklar böyle bir fiili ya da bu fiilin isim kısmını kaydetmemişlerdir.

ilka etmek (ilka etmek) "suadere, persuadere" (438) - mş.: ikna etmek "İnandirmak."

imdad etmek (imdad etmek) "soccorrere" (408) - mş.: imdad etmek "Tehlikede olan birine yardım etmek, yardımcı olmak." 
inkar etmek (inkiar etmek) "renegare" (341) - mş.: inkar etmek "Yaptığın1, söylediğini, tanık olduğunu saklamak, kabul etmemek."

intifak etmek (intifak etmek) "accordare insieme" (11) - mş.: intıbak etmek "Uymak, alışmak."

irca etmek (irgia etmek) "intercedere" (218) - mş.: rica etmek "Ricada bulunmak."

irenk etmek (irengh etmek) "gabbare, ingannare" (158) - mş.: reng etmek arkaik şekli "Oyun etmek, hile yapmak."

irsal etmek (irsal etmek) "mandare" (242) - mş.: irsal etmek "Göndermek, sevkiyat yapmak."

ispat etmek: tekrarden ispat etmek (tekrarden ispat etmek) "riprouare" (354) - mş.: ispat etmek "Kanıtlamak, doğrulamak."

istifra etmek (istifra etmek) "gomito, cioè vomito" (168); istifra etmek (istifra etmek) (360) - mş.: istifră etmek "Kusmak."

işaret etmek (isc-aret etmek) "notare" (272); göziyle işaret etmek (ghiosijle isc-aret etmek) "accennare con glocchi" (7) - mş.: işaret etmek "Bir şeyi, bir durumu el, yüz hareketleriyle anlatmak, göstermek."

işgence [= işkence] etmek (isghenge etmek) "flagellare" (149) - mş.: iş̧kence etmek "Eziyet çektirmek, acı vermek."

kabab etmek (kiabab etmek) "arrostire" (60); kabab etmek (kiabab etmek) "rostire" (364) - mş.: kebap etmek = kebap yapmak "Izgara yapmak."

kabul etmek (kabuletmek) "accettare, ricenere" (8); kabul etmek (kabu 'etmek) "accettare, cioè approuare" (8); kabul etmek (kabul etmek) "essandire" (136); kabul etmek (kabul etmek) "ricenere" (345); dostluge kabul etmek (dostlughe kabuletmek) "accettare per amico" (8); humayate kabul etmek (humaiate kabuletmek) "accettare nella protettione" (8); $k(\imath)$ sayı kabul etmek (ksai kabul etmek) "accettare il partito" (80); mirası kabul etmek (merasi kabul etmek) "accettare leredita" (8); sadet ile kabul etmek (sadetilhe kabuletmek) "accettare, cioè approuare" (8) - mş.: kabul etmek "Razı olmak, onaylamak."

kaht etmek: şehiri kaht etmek (sce-hiri kaht etmek) "affamare città" (23) mş.: kaht "Kıtlık, kuraklık; yokluk."

kal etmek (kal etmek) "refinare" (340) - mş.: kal "Bir alaşımdaki madenlerin erime derecesi farkından yararlanarak bunları birbirinden ayırma işlemi."

kalb etmek (kalb etmek) "falsare, falsificare" (140) - mş.: kalbetmek "1.Bir durumdan başka bir duruma çevirmek, dönüştürmek. 2.Tersine çevirmek, döndürmek." 
kan etmek (kan etmek) "amazzare" (40); kan etmek (kan etmek) "homicidio" (175); kan etmek (kan etmek) "occidere" (277) - mş.: kan etmek arkaik şekli "Öldürmek."

kanun etmek (kanun etmek) "instituire" (217) - mş.: kanun "Yasa, tüzük, norm, kural."

karanluk etmek (karanluk etmek) "infoscare, obscurare" (210); karanluk etmek (karanluk etmek) "offuscare, oscurare" (279); karanlık etmek (charanlik etmek) "oscurare" (285); karanlık etmek (karanlik etmek) "scurare, oscurare" (390) - mş.: karanlık etmek "Karartmak, bir şeyin önünde durarak görünmesine engel olmak."

karg்aşaluk etmek (karghasc-aluk etmek) “fracassare” (153) - mş.: kargaşalık "Kargaşa durumu, anlaşmazlık hâli, münakaşa."

kârlemesi etmek (kiarlemesi etmek) "dissegnare" (124) - Modern kaynaklar böyle bir kullanımı göstermez.

katl etmek (katl etmek) "tagliar la testa" (444) - mş.: kat'etmek "Kesmek, kırpmak, bölmek."

kavġa etmek (chaugha etmek) "rissare" (356); kavgंa etmek (kaughe etmek) "tumultuare" (469); kavgaymen (?) etmek (kaugaimen etmek) "achetare il rumore" (8); buçak kavgası etmek (buciak kaughasi etmek) "accortelare, cioè fare alle cortellate" (11) - mş.: kavga etmek "Münakaşa etmek, dövüşmek."

kavi etmek (kaui etmek) "stabilire, fermare" (428) - mş.: kavi "Güçlü, sağlam, dayanıklı."

kazilik etmek (kasilik etmek) "giudicare" (165) - mş.: kazi = kadl - mş.: kazi = kadl "Hâkim, şeriat hükümlerine göre davalara bakan kimse."

kesindi etmek (kiesindi etmek) "motteggiare, burlare" (264); kesindi etmek (kiesindi etmek) "scherzare, motteggiare" (381) - mş.: kesintiye almak "Biriyle sezdirmeden alay etmek."

kin etmek (kien etmek) "sdegnarsi” (390) -mş.: kin "Kötü niyet, garaz, nefret."

kör etmek (kior etmek) "acciecare" (7); köretmek (kioretmek) "ciecare, acciecare" (90) mş.: kör "Göremeyen."

kurban etmek (kurban etmek) "sacrificare, far sacrifitio" (368) - mş.: kurban etmek "Kurban kesmek; kendi çıkarı için birini veya bir şeyi feda etmek."

lakırdı etmek (lakrdi etmek) "discorrere" (122); lakırdı etmek (lakrdi etmek) "parlamento, ragionamento" (292); lakırdı etmek (lakrdi etmek) "ragionare" (336) mş.: lakırdı etmek "Konuşmak, dedikodu konusu etmek." 
latife etmek (latife etmek) "motteggiare, burlare" (264); latife etmek (latife etmek) "schernire; schernire per burla" (381) - mş.: latife etmek "Şaka etmek."

mahzer etmek (mahser etmek) "processare" (320) - mş.: mahzar "1.Yüksek makamlı bir kimsenin yanı. 2.Adlî rapor."

mamur etmek (mamur etmek) "fortificare" (153) - mş.: ma'mur "Ongun, gelişmiş, bayındır; meskun."

maskaralık etmek (maskaralik etmek) "bessare, schernire" (70); maskaralı etmek (maskaralik etmek) "buffoneggiere, ò fare il buffone" (74); maskaralık etmek (maskaralik etmek) "sbeffare" (374); maskuraluk etmek (maskuraluk etmek) "schernire" (381) - mş.: maskaralık etmek "Saçma sapan şeyler yapmak, soytar1lik etmek."

maslahat etmek: karlye maslahat etmek (karije maslahat etmek) "negotiare vna donna" (269) - mş.: maslahat "Önemli iş, mesele."

matrakculı etmek (matrakgilik etmek) "schermire, scrimere" (381) - Modern kaynaklarda böyle bir fiil ya da bu fiilin isim kısmı mevcut değildir.

mazul etmek (masul etmek) "deponere, metter giu" (115); mazul etmek (masul etmek) "desmettere" (116); mazul etmek (masuletmek) "diporre, cioè metter giu" (120); mazul etmek (masuletmek) "priuare" (319) - mş.: mazul "Azledilmiş olan, işinden çıkarılmış."

mehraba etmek (mehraba etmek) "toccar la mano" (457) - Modern kaynaklarda böyle bir birleşik fiile rastlanmaz.

mekruf etmek (mekruf etmek) "contaminare" (105) - mş.: mekruh "Tiksindirici, iğrenç."

meramet etmek (meramet etmek) "accõmodare, acconciare" (9); meramet etmek (meramet etmek) "accõciare, rifere" (10); meramet etmek (meramet etmek) "racconciare" (334); meramet etmek (meramet etmek) "rapezzare" (338); meramet etmek (meramet etmek) "riparare, rifare" (352); meramet etmek (meramet etmek) "ristanrare" (357); yeyden [= yeniden] meramet etmek (íeiden meramet etmek) "riconciare" (346) - mş.: meramet etmek "Geçici olarak düzeltmek, onarmak."

met etmek (met etmek) "celebrare, magnificare (86); met etmek (met etmek) "laudare, lodare" (228) - mş.: meth etmek "Övmek."

mevlut etmek (meulut etmek) "celebrar, cioè far festa" (86) - mş.: mevlud "Hz. Muhammed'in doğum günü."

minnet etmek (minnet etmek) "ringratiare" (351); minnet etmek (minnet etmek) "supplicare, dimandar in gratia" (443) - mş.: minnet etmek "Birisine boyun eğip yalvarmak." 
mukarer etmek (mukarer etmek) "affermare" (23); mukarer etmek (mukarer etmek) "confermare, ò stabilire" (101) - mş.: mukarrer "1.Kesin, belli, muhakkak. 2.Kararlaşmış, kararlaştırılmış."

mübaşeret etmek (mubasc-eret etmek) "cominciare" (97); mübaşeret etmek (mubasceret etmek) "incominciare, principiare" (203); mübaşeret etmek (mubasc-eret etmek) "ordine, cioè cominciare" (284); mübaşeret etmek (mubasc-eret etmek) "principiare" (318); tekrarden mübaşeret etmek (tekr arden mubasceret etmek) "ricominciare" (346) mş.: mübaşeret "Bir işe başlama, girişme."

mücadele etmek (mugiadele etmek) "questionare, contendere" (333); mücadele etmek (mugiadele etmek) "rissare" (356) - mş.: mücadele etmek "Uğraşmak, savaşmak."

müsevede etmek (museuede etmek) "abbozzare" (4) - mş.: müsvedde "Yazı taslağı, karalama."

nakış etmek (naksc etmek) "miniare" (256); nakış etmek (nakisc etmek) "recamare" (339) - mş.: nakış "1.El işi. 2.Duvar ve tavanları süslemek için yapılan resim."

nalet etmek (nalet etmek) "scommunicare" (386) - mş.: nalet - konuşma dilindeki la'net etmek gibi "İlenmek."

nebedir etmek: namı nebedir etmek (nami nebedir etmek) "suanirs1 i soliti honori" (439) - Modern kaynaklarda bu şekilde bir fiilin olduğunu doğrulayan hiçbir bilgi yoktur.

nebilik etmek (nebilik etmek) "profetizare" (321) - Fiil modern kaynaklarca doğrulanmaz.

netice etmek (netige etmek) "ristringere" (357) - mş.: netice "Sonuç."

nida etmek (nida etmek) "bandire" (67); nida etmek (nida etmek) "grida, cioè bando" (171) - mş.: nida etmek "Çağırmak, seslenmek."

nikâh etmek (nikiah etmek) "sposare" (425) - mş.: nikah etmek "Evlendirmek."

nişan etmek (nsc-an etmek) "notare" (272); nişan etmek (nise-an etmek) "segnare" (393) - mş.: nişan "Belirti, işaret, iz."

paçarız etmek (paciaris etmek) "disturbare" (126); paçarız etmek (paciaris etmek) "impedire" (195); paçarız etmek (paciaris etmek) "ostare, impedire" (286) - mş.: paçarız "Çapraz, dolaşık."

padişahlık etmek (padisc-ahlik etmek) "regnare" (340) - mş.: padişahlık "1.Hükümdarlık. 2.Padişah tarafindan yönetilen ülke."

pak etmek (pak etmek) "santificare" (372) - mş.: pak "Temiz." 
para para etmek (para para etmek) "stracciare, rompere in pezzi" (433) - mş.: parçalamak "Parçalara ayırmak."

pay etmek (pai etmek) "diuidere, spartire" (126); pay etmek (pai etmek) "spartire, diuidere" (417) - mş.: pay etmek "Bölüşmek, paylaşmak, üleşmek." lam."

pek etmek (pek etmek) "indurare, indurire" (207) - mş.: pek "Sert, katı, sağ-

perdah etmek (perdah etmek) "lisciare, polire" (235); perda etmek (perda etmek) (328); sakalı perdah etmek (sakeli perdah etmek) "tondare la barba" (458) - mş.: perdah "Parlatma, parlaklik verme."

peydah etmek (peidah etmek) "generare" (160); peydahetmek (peidahetmek) "procacciare, cercare" (319); peydahetmek (peidahetmek) "produrre, generare" (320); yeyden peydah etmek (ieiden peidah etmek) "regenerare" (340) - mş.: peyda etmek "Sağlamak, oluşturmak, ortaya çıkarmak, edinmek."

pusurenklik etmek (pusurenklik etmek) "ruffianare" (365) - mş.: pezevenklik etmek "Pezevenklik yapmak."

rahatsuz etmek (rahatsus etmek) "scommodare" (385) - mş.: rahatsız etmek "1.Rahatını bozmak. 2.Canını sıkmak."

raks etmek (raks etmek) "ballare, o danzare" (66) - mş.: raks etmek "Dans etmek, oynamak."

razı etmek (rasi etmek) "acconsentire" (10) - mş.: razı etmek "İkna etmek, kabul ettirmek."

reft etmek (reft etmek) "escludere" (135); reft etmek (reft etmek) "priuare" (319) - mş.: reddetmek "Geri çevirmek, kabul etmemek."

resid etmek (resid etmek) "cãcellare, cassare" (78); resid etmek (resitetmek) "casare" (82); resid etmek (resid etmek) "scancellare" (378); resid etmek (resid etmek) "scassare, cassare" (379) - mş.: resid etmek "Ödünç verilen bir paranın iadesi durumunda kaydının silinmesi."

riayet etmek (raiat etmek) "honorare" (176) - mş.: riayet etmek "Uymak, aldırış etmek."

risvay etmek (risuai etmek) "imbrattare, sporcare" (192), risvay etmek (risuai etmek) "suergognare" (441) - mş.: rüsvay "Ayıplanacak durumda olan, rezil.”

rüzgâr etmek (rusghiar etmek) "ventar, far vẽto" (476) - mş.: rüzgar "Havanın yer değiştirmesiyle oluşan esinti, yel."

sabr etmek (sabr etmek) "astenersi" (63); sabr etmek (sabr, etmek) "cõportare, patientemente" (99); sabr etmek (sabr etmek) "comportare" (99); sabr etmek (sabr etmek) "contenere, raffrenare" (105); sabr etmek (sabr etmek) "moderare" 
(259); sabr etmek (sabr etmek) "patire, soffrire" (294); sabretmek (sabretmek) "soffrire" (408); sabretmek (sabretmek) "sopportare" (412); sabr etmek (sabr etmek) "tolerare, soffrire" (458) - mş.: sabretmek "1.Sabır göstermek. 2.Sabırlı davranmak."

sahi etmek (sahi etmek) "accertare, cioè affirmare" (7); sahi etmek (sahi etmek) "accettare, cioè approuare" (8); sahi etmek (sahi etmek) "amendare, cioè correggiere" (41); sahi etmek (sahi etmek) "correggere, emendare" (108) - mş.: sahih "1.Doğru, gerçek, hakiki. 2.Doğru, geçerli."

sakat etmek (sakat etmek) "stroppiare" (437) - mş.: sakat "1.Sağlam olmayan, engelli. 2.Bozuk, hasarl1.

saltanat etmek (saltanet etmek) "glorificare" (166) - mş.: saltanat "1.Bir ülkede hükümdarın, padişahın, sultanın egemen olması. 2.Hakimiyet. 3.İhtişam, görkem."

sarhoş etmek (sc-arhosc etmek) inebriare (207) - mş.: sarhoş "Alkollü içki veya keyif verici bir madde sebebiyle kendini bilmeyecek durumda olan (kimse)."

sefa etmek (sefa etmek) "godere" (167); sefa etmek (sefa etmek) "sguazzare, godere" (403); ziyade safa etmek (szyade safa etmek) "sguazzare, triõfare" (403) - mş.: sefa = safa "Eğlence, zevk, neşe.

seyir etmek (seir etmek) "incantare" (201) - mş.: seyretmek "1.Bakmak, görmek. 2.Yol almak, ilerlemek."

sir etmek (sir etmek) "sacrare, consacrare" (367) - mş.: sır "Giz, gizem."

son etmek (soin etmek) "finire" (148) - mş.: son "1. Sonuncu. 2. Sonuç.

souk etmek (souk etmek) "far tepido" (453) - mş.: soğuk "1.Isısı düşük olan, soğuk hava. 2.Duygudan, sevgiden yoksun olan, yakın ve içten olmayan, ilgisiz."

spat etmek (spat etmek) "prouare, sprimentare" (323) - mş.: ispat etmek "Kanitlamak."

sual etmek (suual etmek) "interrogare” (219) - mş.: sual etmek "Sormak."

suçll etmek (sucili etmek) "colpare, incolpare" (96); suçlı etmek (sueczli etmek) "imputare, incolpare" (198) - mş.: suçlu "Suç işlemiş, kabahatli, mücrim."

sulf etmek (sulf etmek) "achetare la lite" (9) - Modern kaynaklarda böyle bir fiil kaydedilmemiştir.

sultanluk etmek (sultanluk etmek) "dominare" (127) - mş.: sultanlık "1.Sultan olma durumu, padişahlık. 2.Saltanat."

sünnet etmek (sunnet etmek) "circoncidere" (92) - mş.: sünnet etmek 1.Erkek çocukta erkeklik organının ucundaki deriyi çepeçevre kesmek. 2.Düzeltmek." 
şahidetlük etmek (sc-ahidetluk etmek) "testificare" (454) - mş.: şahidlik etmek "Tanıklık etmek."

şamata etmek (sc-amata etmek) "schiamare, schiamazzare" (382) - mş.: şamata etmek "Gürültü patırtı yapmak."

şehit etmek (sc-ehit etmek) "martorizare" (247) - mş.: şehit "İslam dini için savaşta ölen kimse, inancı veya davası için ölen kimse."

şekva etmek (sec-qua etmek) "accusare" (13); sekva etmek (sc-equa etmek) (332) - mş.: şekva "Şikâyet."

şen etmak (sc-en etmak) "allegrare alcuno" (34) - mş.: şen "Neşeli, mutluluk veren."

şerif etmek (serif etmek) "nobilitare" (271) - mş.: şerif "1. Kutsal. 2. Soylu."

şikâr etmek (sc-ikiar etmek) "predare, rapinare" (314) - mş.: şikar "Av, kurban."

şikayat etmek (sc-ikiaiat etmek) "lamentarsi, querelarsi" (226); şikiyat etmek (sc-ikijat etmek) "querelare" (332); şikayat etmek (sc-ikiaiat etmek) "sindicare, accusare" (405) - mş.: şikayet etmek "Yakınmak."

şirin etmek (sc-irin etmek) "addolcire, cioè far dolce" (17) - mş.: şirin "Sevimli, cana yakın, tatlı."

şöhret etmek (sc-ohret etmek) "ornare, adobbare" (285) - mş.: şöhret “1.Ün, nam. 2.Tanınmış, ünlü kimse."

şükür etmek (sc-ukiur etmek) "ringratiare" (351) -mş.: şükretmek "Bir kimseye minnet duymak, Tanrı'ya minnet duygusunu sunmak."

tacib etmek (tagibe etmek) "marauigliarsi” (244); tacib etmek (tagibe etmek) "stupirsi" (438) - mş.: tacib "Şaşkınlık hissi, şaşırma."

taderik etmek (taderik etmek) "preparatione" (316); taderik etmek (taderik etmek) "presentire, antiuedere, indouinare" (317); taderik etmek (taderik etmek) "prouedere" (324); taderik etmek (taderik etmek) "rimediare, prouedere" (349); kemlige tadarik etmek (kiemlighie tadarik etmek) "prouedere al male" (324) mş.: tedarik etmek "Bulmak, sağlamak, temin etmek."

tahrir etmek (tahrir etmek) "pigliare in nota gli paesi" (306) - mş.: tahrir etmek "Kaydetmek, yazmak."

takik etmek (takik etmek) "accertare, cioè affirmare" (7) - muhtemelen mş.: tedkik etmek "İncelemek, araştırmak."

taklit etmek (taklit etmek) "contrafare" (106) - mş.: taklit etmek "Bir kimseye veya bir şeye bağlanmak, taklit yapmak." 
talan etmek (talan etmek) "abottinare" (5); talan etmek (talan etmek) "depredare" (115); talan etmek (talan etmek) "saccheggiare" (366) - mş.: talan etmek "Yağmalamak, soymak."

talim etmek (talim etmek) "essercitare" (137); talim etmek (talim etmek) "instituire" (217) - mş.: talim etmek "1.Öğretmek, bilgi kazandırmak. 2.Alıştırma yapmak."

tamam etmek (tamam etmek) "conchiudere" (99) - mş.: tamam etmek "Tamamlamak, bitirmek, sonlandırmak."

tayin etmek (tain etmek) "deputare" (115); tayin etmek (tain etmek) "destinare" (116); tayin etmek (tain etmek) "diputare; comettere qualche carico" (120) - mş.: tayin etmek "1.Atamak. 2.Kararlaştırmak, belirlemek, ayarlamak."

teftiş etmek (teutisc etmek) "inquisire" (215) - mş.: teftiş etmek "Denetlemek."

telif etmek: kitab telif etmek (kitab telif etmek) "componere, comporre libri" (99) - mş.: telif etmek "Kitap yazmak, derlemek."

tembih etmek (tembeh etmek) "ordinare" (283) - mş.: tenbih etmek "Uyarmak, tembihlemek."

temiz ve pak etmek (temis ue pak etmek) "purgare, nettare" (329) - mş.: temiz, pak "Kirlenmemiş."

tenezzül etmek (tenesul etmek) "abbassare, humiliarsi” (3) - mş.: tenezzül etmek "Alçak gönüllülük göstermek, lütfetmek."

tercime etmek (tergime etmek) "interpretare" (218); tercime etmek (tergime etmek) "tradurre da vna lingua in vn'altra" (462) - mş.: tercüme etmek "Çeviri yapmak."

terk etmek: isden terk etmek (iscden terk etmek) "abbandare limpresa" (3) mş.: terketmek "Ayrılmak, birakmak."

teslim etmek (teslim etmek) "consegnare" (103); sahabına teslim etmek (sahabine teslim etmek) "rendere, restituire" (341); sahabina teslim etmek (sahabina teslim etmek) "ristituire" (357) - mş.: teslim etmek "Bir şeyi sahibine vermek, yerine ulaştırmak."

tez etmek (tes etmek) "spessicare" (420) - mş.: tez "Çabuk, hızla, derhal."

tımar etmek (timer etmek) "acconciare, pulire" (10) - mş.: tımar etmek "Kaşağılamak."

traş etmek (trasc etmek) "radere" (335); traş etmek (trasc etmek) "radere" (338); kalemi traş etmek (kalemi trasc etmek) "temperar la penna" (448) - mş.: tıraş etmek "Tıraş işini yapmak, kesmek." 
ufacuk etmek (vfagiuk etmek) "sminuzzare" (407) - mş.: ufacık "Çok ufak, küçücük."

uzur etmek (vsur etmek) "scusare" (390) - mş.: özür dilemek "Bir işten bağışlanmasını istemek."

vefadarlık etmek (vefadarlik etmek) "corrispondere" (108) - mş.: vefadarlı "Vefa, sadakat, bağl11ık."

vefat etmek (vefat etmek) "morire" (262) - mş.: vefat etmek "Ölmek."

viran etmek (viran etmek) "conculculare" (100); viran etmek (viran etmek) "disertare, cioè guastare affatto" (116); viran etmek (veran etmek) "disertare" (122); viran etmek (viranetmek) "esteerminare" (137); virana etmek (virana etmek) "struggere" (437); birisi viran etmek (birisi viran etmek) "rouinare vno" (364); vilayatı viran etmek (vilaiati viran etmek) "rouinare vn paese" (364) - mş.: viran "Y1k1k, harap."

visali etmek (visali etmek) "render la pariglia" (292) - Modern kaynaklarda sadece visal şekli kaydedilmiştir. visal "Kavuşma, sevgililerin birleşmesi."

yaġma etmek (iagma etmek) "abottinare" (5) - mş.: yağma etmek "Talan etmek."

yahni etmek (iachni etmek) "alessare" (32) - Güncel sözlüklerde sadece filin isim kısmı yahni kaydedilmiştir. mş.: yahni "Kavrulmuş soğan ile pişirilen et yemeği."

yardım etmek (1ardim etmek) "diffendere" (118); yardım etmek (iardim etmek) "soccorrere" (408); yardim etmek (iardim etmek) "soffragare" (409); yardim etmek (iardim etmek) "souenire, aiutare" (415); yardum etmek (iardum etmek) "aiutare" (28) - mş.: yardım etmek "Kendi gücünü, imkânlarını başka birinin iyiliği için kullanmak."

yasak etmek (iasak etmek) "proibire, vietare" (322) - mş.: yasak etmek "Yasaklamak."

yazuk etmek (iasuk etmek) "peccare, fallire" (296) - mş.: yazık arkaik şekli "Günah, kabahat."

yekun etmek (iekun etmek) "sommare" (411) - mş.: yekun "Toplam."

yel etmek (iel etmek) "tirare vn peto" (457) - mş.: yel "Rüzgâr."

yemin etmek (iemin etmek) "giurare" (165) - mş.: yemin etmek "Ant içmek, söz vermek."

yeyden etmek (ieiden etmek) "rifare, cioè far di nuovo" (347) - mş.: yeniden "Gene, yine, bir daha, tekrar." 
(?) yeyil etmek (ïil etmek) "alleggerire" (33) - mş.: muhtemelen yeyni "Hafif, ağır olmayan."

yoldaşlık etmek (ioldasc-lik etmek) "accompagnare" (10) - mş.: yoldaşlık "Yoldaş olma durumu."

zabun etmek (szabun etmek) "sneruare, indebolire" (407) - Modern kaynaklar böyle bir fiili doğrulanmaz.

zapt etmek (sapt etmek) "amministrare, gouernare, regnere" (43); zapt etmek (szapt etmek) "domare" (127); zapt etmek (sapt etmek) "gouernare" (168); zapt etmek (sapt etmek) "ingombrare" (212); zapt etmek (sapt etmek) "reggere, gouernare" (340); zapt etmek (sapt etmek) "frenare, raffrenare" (155); zapt etmek (sapt etmek) raffrenare, retenere (335) - mş.: zaptetmek "Zorla almak, ele geçirmek."

zarar etmek (sarar etmek) "nocere" (271); zarar etmek (sarar etmek) "nuocere" (275); zarar etmek (sarar etmek) "scapitare, perdere in qualche cosa" (379); kimesneye zarar etmek (kimesneie szarar etmek) "offendere, nocere ad alcuno" (279) - mş.: zarar etmek "Maddi ve manevi kayba uğramak."

zarb etmek (sarb etmek) "improntare, imprimere" (197); zarbetmek (sarbetmek) - mş.: zarb etmek "Vurmak, çarpmak."

zem etmek (szem etmek) "biasmare" (72) - mş.: zem "Bir kimseyi kötüleme, yerme, yergi."

zina etmek (szina etmek) "fornicare" (152) - mş.: zina "Aralarında evlilik bağı olmayan kişiler arasındaki cinsel ilişki."

ziyafet etmek (siiafet etmek) "tormentare, dar tormẽto" (459) - mş.: ziyafet "Şölen, resmî yemek; yemekli davet."

zor etmek (szoretmek) "constringere, forzare" (104); zor etmek (sor etmek) "forzare" (153); zor etmek (szor etmek) "riforzare" (347); zor etmek (szoretmek) "sforzare" (402); zor etmek (szor etmek) "violare, per forza" (482); gendisine zor etmek (ghiendisine szoretmek) "sforzarsi" (402) - mş.: zor "1.Çetin, zahmetli, yorucu. 2.Güç, zorlama, kudret."

zulüm etmek (szulum etmek) "angareggiare, grauare" (48) - mş.: zulüm "Kötülük; cefa, zalimlik."

etmemek: Bu fiil etmek fiilinin olumsuz şeklidir. Dolayısıyla aşağıda verilen etmemek fiiliyle yapılmış tüm birleşik fiiller olumsuz bir anlam taşımaktadır.

adavet etmemek (adauet etmemek) "non portar odio" (278) - bkz.: adavet etmek.

dügün etmemek (dughiun etmemek) "non far nozze" (274) - mş.: düğün "Evlenme dolayısıyla yapılan tören." 
ferakat etmemek (ferakat etmemek) "perseuerare" (301) - bkz.: ferakat etmek. hazm etmemek (hasm etmemek) "indigistione" (205) - bkz.: hazm etmek. işaret etmemek (isc-aret etmemek) "non notare" (273) - bkz.: işaret etmek. kabul etmemek (kabul etmemek) "recusare" (340); gabul etmemek (ghabul etmemek) "ripulsare" (354) - bkz.: kabul etmek.

nişan etmemek (niscan etmemek) "non notare" (273) - bkz.: nişan etmek.

terk etmemek (terk etmemek) "perseuerare" (301) - bkz.: terk etmek.

Etmek fiilinin olumsuz şekliyle yapılan birleşik fiiller modern kaynaklarda kaydedilmemiştir.

olmak (olmak) "dimorare, cioè habitare" (119); olmak (olmak) "diuentare" (126); olmak (olmak) "essere" (137); olmak (olmak) "ottenere" (287)

acı olmak (agi, olmak) "amaregiare, diuenire amaro" (39) - mş.: act "Bazı maddelerin dilde bıraktığı yakıcı duyu, tatlı karşı1tı."

aç olmak (agz, olmak) "affamare hauer fame" (23) - mş.: aç "1.Yemek yemesi gereken, acıkmış. 2.Gözü doymaz, haris."

aksak olmak (aksak olmak) "inzoppare" (221) - mş.: aksak "Aksayan, hafifçe topallayan."

asi olmak (asi olmak) "rebellarsi" (339); asi olmak (asi olmak) "ribellarsi" (344) - mş.: asi "İsyankâr, dikbaşl1."

aşılk olmak (asc-ik olmak) "innamorarsi” (214) - mş.: aşılk olmak "Sevmek, tutulmak."

aş(i)na olmak (asc-na olmak) "conoscere" (103) - mş.: aşina, aşna "1.Bildik, tanıdık. 2.Tanışıklık."

bendesi olmak (bendesi olmak) "obligare" (276) - Modern kaynaklar ne böyle bir birleşik fiili ne de bu fiilin isim kısmını gösterir.

bensiz olmak (bensis olmak) "pallidirsi” (289) - mş.: bensiz "Beni/çili olmayan."

beraber olmak (beraberolmak) "vguagliare" (479) - mş.: beraber "Birlikte; aynı düzeyde."

beyan olmak: elmile beyan olmak (elmile beian olmak) "risplendere per virtù" (356) - mş.: beyan "Açılama, anlatım."

boş olmak (bosc olmak) "vacare, esser voto, esser senza" (470) - mş.: boş "Dolu olmayan; sahipsiz."

bir olmak (birolmak) "accoppiare" (10); bir olmak (bir olmak) "congiungere, vnite insieme" (102) - mş.: bir olmak "Birleşmek." 
birlik olunmak (birlik olunmak) "vnirsi" (485) - mş.: birlik"1.Bir olma durumu. 2.Bir arada olma durumu."

borçlı olmak (borgzli olmak) "indebitarsi” (204) - mş.: borçlu "Borcu olan; bir şeyi birinin yardımıyla elde etmiş olan, minnettar."

caleli olmak (gialeli olmak) "rebellarsi" (339) - Modern kaynaklarda böyle bir fiil ve aynı zamanda bu fiilin isim kısmı da kaydedilmemiştir.

cem olmak (gem olmak) "adunare, congregare fare adunaza" (22) - mş.: cem 'etmek filinin edilgen şekli cem' olmak "Toplanmak."

ceset olmak: bir ceset olmak (bir gieset olmak) "incorporarsi” (204) - mş.: ceset "Ölü beden, naaş."

cinli olmak (ginli olmak) "spiritarsi" (423) - mş.: cinli "İçinde cin olduğuna inanılan."

datl olmak (datli olmak) "addolcirsi" (17); datl olmak (datli olmak) "adolcirsi" (127) - mş.: tatl "Şeker tadında olan; hoş, cana yakın."

deli olmak (deli olmak) "impazzire" (195) - mş.: deli olmak "Bir şeye aşırı derecede düşkün olmak."

dilsiz olmak (dilsis olmak) "mutire, diuenir muto" (266) - mş.: dilsiz "Konuşma engelli; ses çikarmayan sessiz olan (kimse)."

dost olmak (dost olmak) "hauere amicitia" (42) - mş.: dost olmak "Ahbap olmak."

dövletli olmak (douletli olmak) "prosperare" (323) - mş.: devletli "Mutluluk ve refah içinde olan (kimse)."

duh(u)l olmak (duhl olmak) "gionta, arriuo" (163) - mş.: duhul "Giriş, girme."

düşmen olmak (disc-men olmak) "innimicarsi” (214) - mş.: düşman "Hasım, rakip."

eskeri olmak (eskieri olmak) "militare, far larte della guerra" (256) - mş.: asker olmak "Askerlik görevine başlamak."

ey(i) olmak (ei olmak) "star bene" (430) - mş.: iyi olmak "1.İyileşmek, hastal1ktan kurtulmak. 2.Yerinde olmak. 3. Uygun gelmek."

fakir olmak (fakir olmak) "impouerire" (197) - mş.: fakir "Geçimini güçlükle sağlayan, yoksul."

genç olmak (giengz olmak) "ringiouenire" (351) - mş.: genç "Yaşı ilerlememiş olan."

günahsuz olmak (ghiunak sus olmak) "scolpare, discolpare" (385) - mş.: günahsız "Kabahatsiz, suçsuz." 
hain olmak (chain olmak) "rebellarsi" (339) - mş.: hain "Hıyanet eden kimse, kalleş; kötü niyeti olan."

hasta olmak (chasta olmak) "ammalare, ammalarsi" (39) - mş.: hasta olmak "Hastalanmak."

hazır olmak: kaçmaġa hazır olmak (kacimagha haszir olmak) "apparecchiarsi a fugire" (54) - mş.: hazır "Bir iş yapmak için gereken her şeyi tamamlamış olan, Belli bir işe yarayacak, kullanılacak bir duruma getirilmiş."

hiç olmak (hecz olmak) "suanire, riuscire in niente" (439) - mş.: hiç olmak "1.Yok olmak. 2.Helak olmak, nesli tükenmek."

1rsuz olmak (irsus olmak) "essere infame" (208) - Modern kaynaklarda böyle bir birleşik fiil kaydedilmemiştir. Muhtemelen 1rsuz 1rz köküne -suz ekinin eklenmesiyle türetilmiştir.

iş üstüne olmak (isc vstune olmak) "negotiare, far facende" (269) - Bu deyim modern kaynaklarda kaydedilmemiştir fakat bu fiili oluşturan tüm kelimeleri bilinmektedir.

imani olmak (imani olmak) "pieta, diuotione" (305) - mş.: iman "İnanç, iman."

ircası kabul olmak (irgiasi kabul olmak) "impetrare, ottenere" (196) - Anlamca kaynaşmış bu birleşik fiile modern kaynaklarda rastlanmaz. Hatta kabul olmak birleşik fiili bile güncel sözlüklerde görünmez fakat deyimin isim kısmı bilinmektedir ve sözlüklerde tespit edilmiştir. mş.: irca "Eski biçimine sokma." kabul "Onama."

kadir olmak (kadir olmak) "osare, ardire" (285); kadir olmak (kadir olmak) "kadir olmak" (313); kadir olmak (kadir olmak) "valere, potere" (471) - mş.: kadir olmak "Gücü yetmek, güçlü olmak."

kadid olmak (kadid olmak) "indurirsi per il freddo" (207) - mş.: kadid "Deri ve kemik; iskelet."

kalın olmak (kalin olmak) "ingrossarsi” (213) - mş.: kalın "İnce karşıtı."

kehel olmak (kiehel olmak) "impigrire, cioè diuenir pigro" (196) - mş.: kehel "Üşsengeç."

kem olmak (kiem olmak) "peggiorare" (297) - mş.: kem "Kötü, fena."

$k($ ( ) lav (u)z olmak (klaus olmak) "menare, guidare” (251) - mş.: kılavuz "Rehber, yol gösteren."

köylü olmak (kioulu olmak) "rusticare, star in villa" (366) - mş.: köylü "Köyde yaşayan veya köyde doğmuş olan."

kuvetlü olmak (kuuetlu olmak) "vigoreggiare, esser nel suo vigore" (480) mş.: kuvvetli "Güçlü, dayanıklı olan." 
kül olmak (kiul olmak) "in cenerire” (201)- mş.: kül olmak "Bütünüyle yanmak."

layık olmak (laik olmak) "meritare" (252) - mş.: layık "Nitelikleri, özü, hareketleri, davranışlarıyla bir şeyi elde etmeye hak kazanmıl olan; uygun."

magrur olmak (maghrur olmak) "in alzarsi, cioè insuperbirsi” (199) - mş.: mağrur olmak "Gururlanmak." k1n."

mail olmak (mail olmak) "inclinatione" (202) - mş.: mail "Eğilimi olan, yat-

maskara olmak (maskara olmak) "immascararsi" (193); maskara olmak (maskara olmak) "maskararsi” (248) - mş.: maskara olmak "Gülünç duruma düşmek.

maslahat olmak (maslahat olmak) "ottenere" (287) - mş.: maslahat "Önemli iş, mesele."

mehman olmak (mehman olmak) "riposare" (353) - Bu birleşik fiil ve onun isim kısmı da modern kaynaklarda mevcut değildir.

mestane olmak (mestane olmak) "imbricare" (192) - mş.: (sadece): mest olmak "Kendinden geçmek."

milk sahabi olmak (milk sahabi olmak) "regnare" (341) - mş.: mülk sahibi "Emlak ve arazi sahibi."

mukabile olmak (mukabilhe olmak) "incontrarsi" (204) - mş.: mukabil "Bir şeyin karş1lığı olan."

mukayat olmak (mukaiat olmak) "affissato, affisso" (24); mukayet olmak (mukaiet olmak) "impiegare" (196); mukayet olmak (mukaiet olmak) "procurare, sollecitare" (320) - mş.: mukayyet olmak "Bağlı olmak, bağlanmak."

muti olmak (muthe olmak) "humigliare, abassare" (177); muti olmak (muteh olmak) "vbedire" (473); muti olmak (muthe olmak) "obedire" (276) - mş.: muti "Yumuşak başl1, itaat eden."

mürüd olmak (miurud olmak) "seguitare" (393) - mş.: mürüd "İstekli, arzulu." müşeref olmak (musc-eref olmak) "riuedersi” (359) - mş.: müşerref olmak "Şereflenmek."

napak olmak: maryolligile napak olmak (mariollighilhe napak olmak) "sporcarsi di ribaldaria" (424) - mş.: napak "Temiz olmayan, kirli, murdar."

nebedir olmak (nebedir olmak) "suanire, riuscire in niente" (438/439) - Modern kaynaklarda ne bu birleşik fiile ne de bu fiilin isim kısmına rastlanmıştır.

püşman olmak (pusc-man olmak) "pentirsi” (299) - mş.: pişman "Müteessir, üzgün, nadim." 
rahat olmak (rahat olmak) "posare, riposare" (312); rahat olmak (rahat olmak) "reposare" (342); rahat olmak (rahat olmak) "riposare" (353) - mş.: rahat "İnsanda üzüntü, sıkınt1, tedirginlik olmama durumu, huzur, dinginlik."

sag olmak (sagholmak) "sanarsi" (371); sag ol (saghol) "stà sano" (428) mş.: sağ olmak "Hayatta olmak, eli ayağı tutmak."

sag்duc olmak (saghdugz olmak) "tenere à battesimo" (451) - mş.: sağglç. ${ }^{9}$

sahab olmak (sahab olmak) "impadronirsi" (194); sahab olmak (sahab olmak) "insignorirsi” (216) - mş.: sahib " 1.Hamil. 2. Herhangi bir şey üstünde mülkiyeti olan, onu yasaya uygun bir biçimde dilediği gibi kullanabilen kimse. 3 . Yöneten, gözeten kimse."

sarhoş olmak (sarhosc olmak) "imbricare" (192); sarhoş olmak (sc-arhosc, olmak) - mş.: sarhoş "Alkollü içki veya keyif verici bir madde sebebiyle kendini bilmeyecek durumda olan (kimse)."

sergarden olmak (szerghiarden olmak) "disuiarsi” (126) - mş.: sergerdan "1.Başı dönen. 2. Kafası karışmış, şaşkın.

suçsuz olmak (suczsus olmak) "scolpare, discolpare" (385) - mş.: suçsuz "Suçu olmayan, masum."

sulf olmak (sulf olmak) "accordarsi col suo creditore" (11) - mş.: sulh "1.Huzur, barış, uzlaşma. 2.Anlaşma.

sus olmak (sus olmak) "silentio" (404) - mş.: sus "Suskun, sessiz."

süküt olmak (sukiut olmak) "tacere, star quieto" (444) - mş.: sükut "Sessizlik." 11."

şirin olmak (sc-irin olmak) "addolcire, cioe far dolce" (17) - mş.: şirin "Tat-

şişko olmak (sc-isc-ko olmak) "ingrossarsi" (213) - mş.: şişko "Şişman."

tavlu olmak (taulu olmak) "vigoreggiare, esser nel suo vigore" (480) - mş.: tavll "En iyi durumda."

tebdil olmak: suret tebdil olmak (suret tebdil olmak) "strauestirsi, mascararsi” (435) - mş.: tebdil "Değiştirme, değişim."

teslim olmak (teslim, olmak) "confidarsi" (101) - mş.: teslim olmak "Boyun eğmek, üstün bir güç karşısında mücadeleden vazgeçip yenilgiyi kabul etmek."

tok olmak (tok olmak) "satiare" (373) - mş.: tok olmak "Doymak, karnı tok olmak."

9 Ç.N. : sağdıç ol- birleşik fiilini Molino “tenere à battesimo" vaftiz etmek anlamını vermektedir. Sağdıç Türkçede ise "Dügünde gelin veya güveye k1lavuzluk eden kişis." anlamında kullanılır. (bkz. Türkçe Sözlük, Ankara, TDK Yayınları, 2010, s. 2004). 
usullı olmak: usullı ol (vsulli ol) "stà in ceruello" (428) - mş.: usullü "Sistemli, yöntemli."

üstüne olmak (vstune olmak) "premere, cioè sollecitare" (315); üstüne olmak (vstune olmak) "procurare, sollecitare" (320); üstüne olmak (vstune olmak) "sollecitare" (410); üstüne olmak (vstune olmak) "spronare" (426); üstüne olmak (vstune olmak) "stimolare, sollecitare alcuno" (432) - Modern kaynaklarda böyle bir anlamca kaynaşmış birleşik fiil kaydedilmemiştir; ancak bu birleşik fiilin isim kısmı modern dilde bilinmektedir ve çok yaygın kullanılır. mş.: üstüne - üst sözcüğünün yönelme hâli eki almış şekli "Bir şeyin yukarı, göğe doğru olan yanı, alt karşı1t.."

vasıl olmak (vasil, olmak) "arriuare \& aggiungere" (60) - mş.: vasıl olmak "Varmak, ulaşmak."

$v(u) k u f i$ olmak (vkufi olmak) "pratica, esperienza" (314) - mş.: vukuf "Anlama, bilme."

yakın olmak (iakin olmak) "auicinarsi" (64) - mş.: yakın "Aralarında az bir ara olan."

yavuz olmak (iaus olmak) "adirarsi, crucciarsi” (19) - mş.: yavuz "Zalim, acımasiz."

zabun olmak (szabun olmak) "debilitare, indebolire" (114); zabun olmak (sabun olmak) 'fiaccare, indebolire” (145) - Güncel kaynaklar ne zabun sözcüğünü ne de bununla oluşturulmuş birleşik fiilleri gösterir.

zalim olmak (szalim olmak) "incrudelirsi” (204) - mş.: zalim "Haksız davranan, acımasiz, zulmeden."

zayi olmak (szai olmak) "perire, ponire" (300) - mş.: zayi olmak "Yitmek, helak olmak."

Olmamak olmak fiilinin olumsuz şeklidir.

bendesi olmamak (bendesi olmamak) "non obligarsi” (276)

birlik olmamak (birlik olmamak) "seditione, discordia" (392); birlik olmamak (birlik olmamak) "zizania, discordia" (493)

muti olmamak (muthe olmamak) "non obedire" (276)

tabi olmamak (tabi olmamak) "disubedire" (126) - mş.: sadece: tabi olmak "Birinin kontrolü altına girmek, bir şeye veya bir kimseye bağlı olmak."

Modern kaynaklarda olmak yardımcı fiiliyle yapılan birleşik fiillerin olumsuz şeklini gösterilmez, bu fiillerin olumlu anlam taşıyan eşdeğerleri nadiren gösterilmiştir.

Modern Türkçede eylemek fiili çok nadir görülür. Aslında eylemek fiili yap- 
mak ve etmek fiillerinin eşdeğeridir. Molino'nun sözlüğünde bu fiile yardımcı fiil olarak yalnızca bir deyimde rastlarız.

eylik eyle (eiligh eile) "fa bene" (139) mş.: eylemek "Yapmak, etmek. İyilik yapmak ile karşılaştırınız.

Molino kılmak fiilini yardımcı fiil olarak iki deyimde kullanmıştır:

ölüyi diri kılmak (olui deri klmak) "resuscitare" (343); ölüyi diri kılmak (olui diri klmak) "risuscitare" (357). Bu deyim modern dilde mevcut değildir.

secde k1lmak (secsde glmak) 'adorare' (20) - mş.: secde etmek “Alnı, eli, ayakları, dizleri, ayak parmaklarını yere getirmek.

Toplanan örneklerin incelemesi Osmanlı Türkçesinin modern Türkçe ile karşılaştırılması hususunda bazı açıklamalara neden olmuştur.

Tespit edildiği kadarıyla Osmanlı Türkçesinde etmek fiilinin yardımcı fiil görevinin çok yaygın olduğunu söyleyebiliriz. Molino'nun sözlüğünde etmek (fiilini) kullanan deyimler de dahil olmak üzere takribi 246 birleşik fiil tespit ettik. Bu şekillerin yaklaşık olarak \%48'i modern Türkçede hâlâ kullanılmaktadır; bu sebepten dolayı etmek fiili bu özellikte kullanımını hâlâ devam ettirmektedir. 17. Yüzyıl örneklerinin yaklaşık olarak \%39'u birleşik fiilleri oluşturur; fakat bu birleşik fiiller modern kaynaklarda doğrulanmaz, ancak bu fiillerin isim k1sımları bilinmektedir ve kaydedilmiştir. Lakin, bu dilin gelişim süreci esnasında etmek'li birleşik fiillerin büyük olasılıkla yenisiyle, tek kelimelik fiil türevi ya da yeni türetilen kelime ile yer değiştirmiş olmasıyla açıklanabilir. İncelenen birleşik fiillerin sadece \%4'ü modern kaynaklarca doğrulanmamıştır. Yine de Molino tarafından düşülen hataların bazı yapıların tanımlanmasını imkansız hâle getirilebileceği gerçeğini yok sayamayız. Olmak fiilinin oluşturduğu birleşik fiil grubu etmek fiiliyle oluşturulan yapılara kıyasla sayıca az olup sadece 88 örnekte görülmüştür. Ancak, olmak fiilinin kullanımı sadece semantik bakış açısından bakıldığında etmek birleşik fiilinin yerine de geçebileceği aşikârdır çünkü bunlar dönüşlülük şeklini oluştururlar (Karşılaştırınız örneğin Stachowski ${ }^{10}$ ). Bu yüzden, Molino tarafindan kaydedilen olmak ile oluşturulmuş birleşik fiillerin sadece \%28'inin modern kaynaklarda mevcut olması hiç şaşırtıcı değil. Ancak, olmak yardımcı fiiliyle yapılan birleşik fiillerin isim kısımlarının çoğu, yaklaşık olarak \%72'si, modern kaynaklarda kaydedilmiştir.

İncelememiz göstermiştir ki tarihi Türk dilinde (Osmanlı Türkçesinde) etmek ve buna oranla daha az kullanılan olmak gibi filler isim unsurlarıyla birlikte kullanıldığında genellikle çok sayıda söz öbeği ve deyimlerde görülen birleşik fiiller oluşturur.

10 Marek Stachowski, Gramatyka Jezyka Tureckiego w Zarysie, Kraków, 2007, s. 246. 
Tarihî şekillerin çoğu modern kaynaklarda hâlâ mevcuttur; ancak tek başına yardımcı fiiller kullanan fiilleri oluşturma eğilimi Osmanlı Türkçesindeki kadar çok değildir.

\section{Kisaltmalar}

bkz. Bakınız.

Ç.N. Çevirenin notu

Günl. Günlük

mş. Modern şekli

vb. ve benzerleri 


\section{Kaynakça}

Adamović, Milan, Das Türkische des 16. Jahrhunderts Nach den Aufzeichnungen des Florentiners Filippo Argenti, Göttingen, 1533/2001.

Adamović, Milan, "Giovanni Molino Und Seine Türkische Grammatik", Acta Linguistica Academiae Scientiarum, cilt 24, 1974, s. 37-67.

Dilaçar, Agop, Türk Diline Genel Bir Baklş, Ankara, 1964.

Gencan, Tahir Nejat, Dilbilgisi, İstanbul, 1971.

Göksel, Asl1 - Kerslake, Celia, Turkish: A Comprehensive Grammar, London, New York, 2005.

Lewis, Geoffrey, Turkish Grammar, Oxford, 1975.

Majda, Tadeusz, Rozwój Jezyka Tureckiego w XVII wieku, Warszawa, 1985.

Majda, Tadeusz, Jezyk Turecki, Warszawa, 2001.

Preto, Paolo, Venezia e i Turchi, Firenze, 1975.

Redhouse Yeni Türkçe-İngilizce Sözlük, İstanbul, 1981.

Siemieniec-Gołaś, Ewa, Turkish Lexical Content In Dittionario Della Lingua Italiana, Turchesca by Giovanni Molino (1641), Kraków, 2005.

Stachowski, Marek, Gramatyka Jezyka Tureckiego w Zarysie, Kraków, 2007.

Święcicka, Elżbieta, “Interpreter Yovhannes Ankiwrac’i also called Giovanni Molino", Folia Orientalia, cilt 36, 2000, s. 329-342.

Tanış, Asım, Giovanni Molino'nun Ittalyanca-Türkçe Sözlügü ve Halk Türkçesi, Ankara, 1989. 
